\section{Commentary: Positive bronchial section margin: How certain is R uncertain?}

\author{
Paul E. Van Schil, MD, PhD
}

Bronchial sleeve resection is a valid alternative to pneumonectomy on the condition that a complete $\mathrm{R} 0$ resection can be obtained, as defined by a working group of the International Association for the Study of Lung Cancer (IASLC) in 2005. ${ }^{1}$ Generally, during the intervention, a frozen section analysis of the bronchial section planes is obtained to document free margins. What is the clinical significance and prognosis of patients with microscopic residual disease at the anastomotic site? Is there a difference between carcinoma in situ and invasive carcinoma? The data in the literature are quite sparse. In the series of Massard and colleagues, ${ }^{2} 7.9 \%$ had positive resection margins, and most of these patients died of progressive disease. The authors also reported that carcinoma in situ at a bronchial stump (mutatis mutandis, this also applies to sleeve resections) does not influence survival.

In the present large and well-described series of 540 patients who underwent sleeve resection between 1995 and 2015, 40 patients $(7.4 \%)$ had R1 residual disease. ${ }^{4}$ Fiveyear overall survival and recurrence-free survival did not differ between patients with R0 and R1 resection. In addition, the recurrence rate at the bronchial anastomosis did not differ between the groups. Invasive extramucosal involvement was associated with a higher recurrence rate. The general conclusion was that oncologic outcome of microscopic residual disease was not jeopardized.

Hong and colleagues are to be commended for providing a detailed evaluation of their patient population and thorough statistical analysis. Nonetheless, this is a retrospective, single-institution study with a limited number of patients with $\mathrm{R} 1$ resection, which in itself consists of a heterogenous

\footnotetext{
From the Department of Thoracic and Vascular Surgery, Antwerp University Hospital and Antwerp University, Antwerp, Belgium.

Disclosures: Author has nothing to disclose with regard to commercial support.

Received for publication March 4, 2020; revisions received March 7, 2020; accepted for publication March 10, 2020; available ahead of print March 19, 2020.

Address for reprints: Paul E. Van Schil, MD, PhD, Department of Thoracic and Vascular Surgery, Antwerp University Hospital, Wilrijkstraat 10, B-2650 Edegem, Antwerp, Belgium (E-mail: paul.van.schil@uza.be).

J Thorac Cardiovasc Surg 2021;161:278-9

$0022-5223 / \$ 36.00$

Copyright (c) 2020 by The American Association for Thoracic Surgery

https://doi.org/10.1016/j.jtcvs.2020.03.014
}

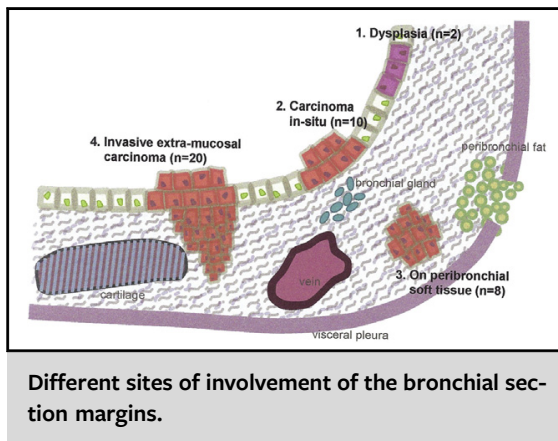

CENTRAL MESSAGE

A positive bronchial section margin ranges from $\mathrm{R}$ uncertain to R1 or R2 involvement with different prognosis.

group ranging from carcinoma in situ at the bronchial anastomosis to frank invasion.

Quite interestingly, the authors report that the number of recurrences increased as the location of residual carcinoma changed from the endobronchial side to the outer bronchial wall (Figure 1). Although not statistically significant, overall survival and recurrence-free survival were lower in cases of $\mathrm{R} 1$ resection. Generally, in contrast to R2 resection comprising macroscopic residual disease, the significance of R1 involvement has not been firmly established. Moreover, in 2005, the IASLC defined an intermediate category called Run, or uncertain resection, with a prognosis in between that of R0 and R1. ${ }^{1}$ Carcinoma in situ belongs to this category. In a recently published repeat analysis of the IASLC database, the $\mathrm{R}$ descriptors were reported to have prognostic relevance, with uncertain resections stratifying between R0 and R1 resections ${ }^{5}$; however, there were only 13 cases with carcinoma in situ at the bronchial margin.

Although Hong and colleagues do not explicitly state it, their paper provides additional data to include patients with carcinoma in situ at the bronchial margin in the $\mathrm{R}$ uncertain category with a better prognosis than those patients with R1 disease due to microscopic invasive carcinoma at the resection margin. However, still more convincing data are needed to determine the real prognostic significance of $\mathrm{R}$ uncertain and to recommend the best adjuvant therapy, especially in the new era of targeted therapies and immunotherapy.

\section{References}

1. Rami-Porta R, Wittekind C, Goldstraw P. Complete resection in lung cancer surgery: proposed definition. Lung Cancer. 2005;49:25-33. 


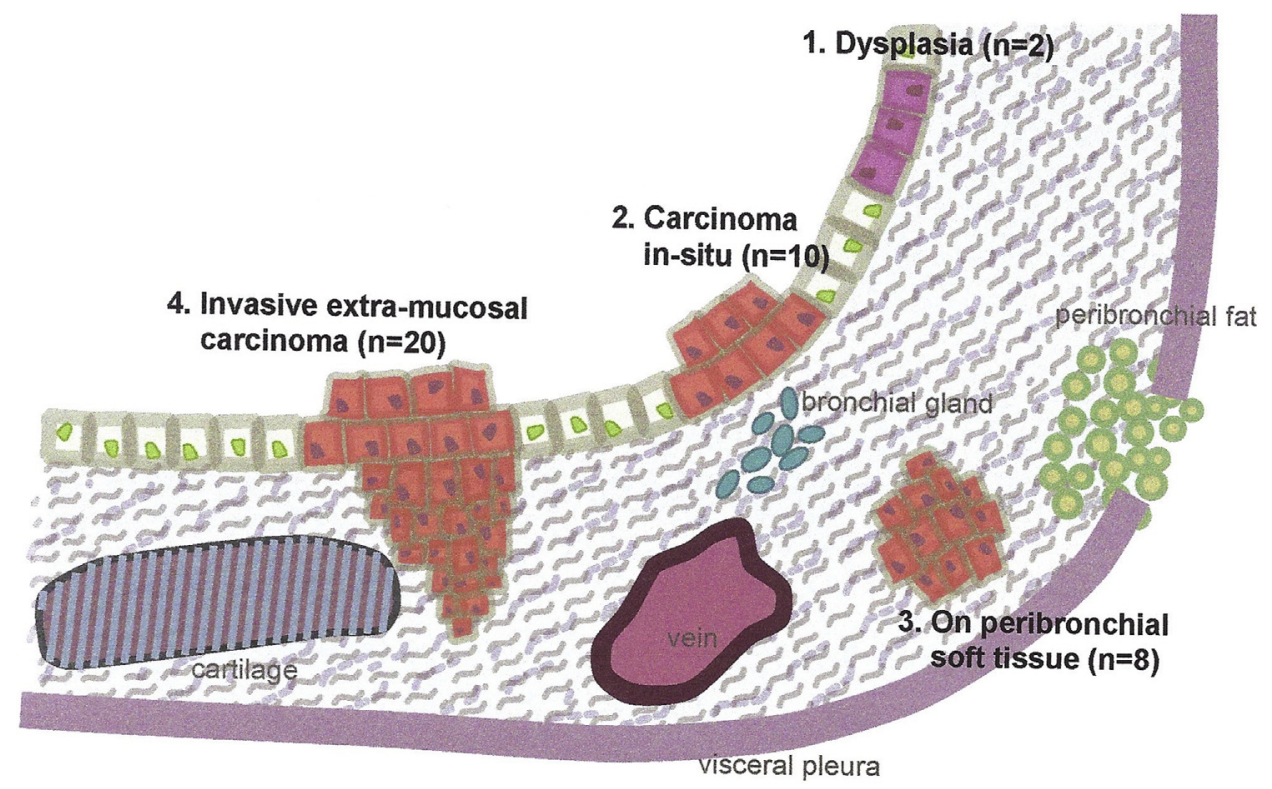

FIGURE 1. Different sites of involvement of the bronchial section margins.

2. Massard G, Kessler R, Gasser B, Ducrocq X, Elia S, Gouzou S, et al. Local control of disease and survival following bronchoplastic lobectomy for non-small cell lung cancer. Eur J Cardiothorac Surg. 1999;16: 276-82.

3. Massard G, Doddoli C, Gasser B, Ducrocq X, Kessler R, Schumacher C, et al. Prognostic implications of a positive bronchial resection margin. Eur J Cardiothorac Surg. 2000;17:557-65.
4. Hong TH, Kim J, Shin S, Kim HK, Choi SY, Zo JI, et al. Clinical outcomes of microscopic residual disease after bronchial sleeve resection for non-small cell lung cancer. J Thorac Cardiovasc Surg. 2021;161:267-77.e9.

5. Edwards JG, Chansky K, Van Schil P, Nicholson AG, Boubia S, Brambilla E, et al. The IASLC lung cancer staging project: analysis of resection margin status and proposals for residual tumor descriptors for non-small cell lung cancer. J Thorac Oncol. 2020:15:344-59.

\section{Commentary: Absence of evidence is not evidence of absence}

Vignesh Raman, MD, and Oliver K. Jawitz, MD

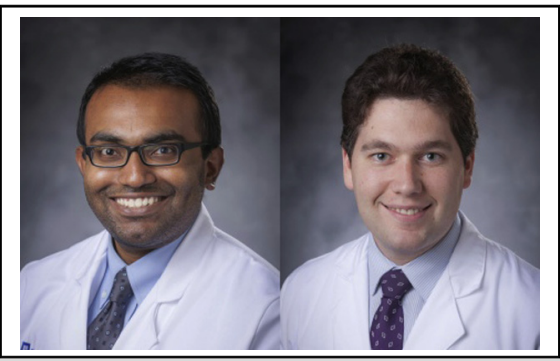

Vignesh Raman, MD, and Oliver K. Jawitz, MD

CENTRAL MESSAGE

Although microscopically posi-

tive bronchial margins were not associated with worse survival in this study, only 28 patients had invasion at the margin, making the data difficult to interpret. 